THE EFFECT OF PRE-CONSUMPTION MOOD AND SERVICE RECOVERY MEASURES ON CUSTOMER EVALUATIONS AND BEHAVIOR IN A STRATEGIC ALLIANCE SETTING

Karin Weber

Assistant Professor

School of Hotel and Tourism Management

Hong Kong Polytechnic University

Hung Hom, Kowloon

Hong Kong, SAR, China

Tel: + (852) 2766 4031; Fax: + (852) 23629362

Email: hmkweber@polyu.edu.hk

Beverley Sparks

Professor, Griffith Business School

Services Industry Research Centre

Griffith University, PMB 50, GCMC, 9726, QLD

Australia

Tel: +(61) 75552 8766; Fax: +(61) 755528978

Email: B.Sparks@griffith.edu.au 


\title{
THE EFFECT OF PRE-CONSUMPTION MOOD AND SERVICE RECOVERY MEASURES ON CUSTOMER EVALUATIONS AND BEHAVIOR IN A STRATEGIC ALLIANCE SETTING
}

\begin{abstract}
In recent years researchers have devoted considerable attention to the study of service failure and recovery (Smith, Bolton and Wagner 1999), predominantly focusing on the impact of a single service failure event. More recently, several researchers have begun to investigate how multiple service failures over an extended time period influence consumer evaluations (Maxham \& Netenmeyer, 2002). However, current research has ignored the impacts of service failures and recovery measures in situations in which two or more service organizations are involved in the service provision, as is the case in a strategic alliance setting. The present study reports on an experiment that investigated the impact of pre-consumption mood and service recovery measures on consumer evaluations in an airline alliance setting. The implications of the study results, both theoretical and managerial, will be discussed and future research directions proposed.
\end{abstract}

KEYWORDS: Service failure and recovery, alliances, pre-consumption mood 


\section{INTRODUCTION}

In recent years researchers have devoted considerable attention to the study of service failure and recovery (SF/R) (De Wit \& Brady, 2003; Smith, Bolton, \& Wagner, 1999; Tax, Brown, \& Chandrashekaran, 1998), due in part to its critical impacts on customer satisfaction (McCoullough, Berry, \& Yadav, 2000), word-of-mouth (Blodgett, Hill, \& Tax 1997), and repeat purchase intentions (Keaveney, 1995). Early research in the field focused on the classification of service failures and recovery measures (Bitner, Booms, \& Tetreault, 1990), and was further expanded when justice theory, and more recently fairness theory (McColl-Kennedy \& Sparks, 2002) were introduced. On that basis, potentially effective service recovery measures in achieving customer satisfaction, positive word-of-mouth, repeat purchase, and loyalty have been identified (Blodgettt, et al., 1997; Boshoff \& Leong, 1998; Smith \& Bolton, 1998). The vast majority of previous research has concentrated on the impact of a single service failure event, in part facilitated by the critical incident technique. More recently, researchers have begun to investigate how multiple service failures over an extended time period influence consumer evaluations (Mittal, Katrichis, \& Kumar, 2001; Mittal, Kumar, \& Tsiros, 1999), consistent with the notion of a distinction between encounter and cumulative satisfaction (e.g., Bitner \& Hubbert, 1994).

However, in services marketing the individual firm-customer dyad has remained the contextual focus of much of the extant research (Gitell, 2002). Only recently have service researchers begun to examine provider-provider relationships and their impact on consumer evaluations and behavior (Gitell, 2002; Smith \& Tax, 2005). In a single service provider setting, a service firm has direct control over the quality of its service provision and relationship-building efforts. In contrast, in a strategic alliance setting, a service provider relinquishes this direct control by encouraging its customers to use the services of an alliance partner (Weber, 2002). In order to ensure that a service firm's membership in a strategic alliance is beneficial to, rather than detracting from its competitive position in the long-term, an understanding of potential impacts of a service failure by an alliance partner is critical.

Drawing on theory and research into the role of affective states, justice, and attribution, this article will provide insights into how consumers' pre-consumption mood and certain service recovery actions impact on consumer evaluations and behavior. In doing so, the present study seeks to extend the existing research focus from a single to a multiple service provider context, consistent with recent trends in the business environment that requires an understanding of consumers' evaluations and behaviors towards multiple service providers that are linked in the 
provision of services. The travel industry is a classic example of the trend to form alliances which result in a customer being exposed to several different airlines in one international trip; these airlines are grouped together as a single, brand alliance. The article is structured as follows: First, the article reviews the literature pertaining to each of the variables of interest, leading to the development of hypotheses guiding this research. Second, the research design is detailed. Third, study results are discussed. Finally, managerial implications and directions for future research are outlined.

\section{LITERATURE REVIEW}

\section{Pre-Consumption Mood}

Previous research has typically focused on service failure events only, with a subsequent assessment of satisfaction, word-of-mouth, and repeat purchase intentions (Smith et al., 1999). However, in the tourism literature reference is made to consumers' assessment of an entire travel experience where experiences with individual service providers such as airlines, hotels, restaurants, and local transportation interact and combine to an overall assessment of the travel experience (Otto \& Ritchie, 1996). Furthermore, other individual factors such as the mood a consumer is in prior to the service encounter with the provider under investigation may potentially have an impact on his/her assessment of that particular entity.

Both moods and emotions are grouped under affect, a general category for mental feeling processes (Cohen \& Areni, 1991). Bagozzi, Gopinath, \& Nyer (1999) defined emotions as mental states of readiness that arise from cognitive appraisals of events or one's own thoughts - distinct from moods, in that the latter tend to be lower in intensity and less arousing, are generally non-intentional, do not have a specific referent, and are not as directly coupled with action tendencies as the former (Frijda, 1993; Gardner, 1985). Moods are also less transient than emotions (Bagozzi et al., 1999), and are typically conceptualized as two different dimensions only: positive versus negative moods.

The impact of customers' affective states on their service evaluations (Andreassen, 2000) and satisfaction processes (Mano \& Oliver, 1993; Oliver, 1993; Westbrook \& Oliver, 1991; Wirtz \& Bateson, 1999) has been investigated as has, to a lesser extent, the influence of customers' affective responses to service failures on their evaluations of various types of recovery efforts and satisfaction with the service encounter (Dube \& Maute 1996; Hui \& Tse 1996; Smith \& Bolton, 2002; Taylor 1994). Common to all these studies is the assessment of emotions as a result of a service encounter/failure with a service provider. To date, there are only two studies that have 
assessed the effect of pre-consumption affect on service evaluations. Mattila and Wirtz (2000) examined the impact of pre-consumption affect elicited by environmental elements on consumers' post-purchase evaluation. In particular, they assessed how two basic dimensions of affect - pleasure and arousal - contribute to customer evaluations of different types of services. Their findings suggested that the influence of arousal on post-purchase evaluations depends on the level of pleasure experienced in the pre-consumption service stage. However, the authors also conceded that the relatively small sample size and the use of four different service settings may have limited the conclusions that can be drawn from the study findings.

In related research, Liljander and Mattson (2002) examined the impact of preconsumption mood on the evaluation of three service behaviors (concern, congeniality, and incivility) and satisfaction. They found that customer mood has a dual effect on service encounter evaluation, as it directly affects the evaluation of employee behavior as well as overall satisfaction. Of particular interest to the current study were two suggestions for further research. Liljander and Mattson (2002, p. 855) argued that due to potentially asymmetrical effects of mood on service evaluations "customers who are in a bad mood possibly pay more attention to uncivil employee behavior," such as low interactional justice, and, therefore, may be more negative in their evaluations and behavior towards the offending firm. The authors also point to the potential influence of mood-maintenance (Bagozzi et al., 1999) whereby customers who are in a good mood may wish to maintain that mood and therefore, focus on the positive aspects of the service interaction or past high quality performance.

In both studies (Liljander \& Mattson, 2002; Mattila \& Wirtz, 2000) pre-consumption affect was caused by actions of the particular service provider who was subsequently evaluated. In contrast, our study extends current research by assessing the impact of pre-consumption mood caused by a combination of environmental factors and the actions of a service provider on the customer's affective state prior to his/her subsequent evaluations of another service provider.

The discussion turns now to the second factor that may potentially affect consumer evaluations and behavior in an alliance context; the type of recovery strategies employed by one of the airline alliance partners. 


\section{Service Recovery Strategies}

Research in justice within organizations dates back about 30 years and has its origins in social psychology. In the past, it has been especially utilized in legal and organizational settings. Its application in service industry settings is much more recent (e.g., Smith et al., 1999; Sparks \& McColl-Kennedy, 1998; Tax et al., 1998), based on the notion that customers' evaluations, such as fairness and satisfaction, and behaviors, such as word-of-mouth communication and loyalty, are dependent on whether they feel that justice has been done and consequently, they have been treated fairly (McColl-Kennedy \& Sparks, 2001). Three types of justice have been commonly identified. Distributive justice is a justice dimension that has its origin in social exchange theory that emphasizes the role of exchange considerations as a key influence on interpersonal relations (Adams, 1965). It relates to people's perceptions of the fairness of the outcomes they receive or resource distribution decisions. Introduced in legal settings by the seminal work of Thibaut and Walker (1975), procedural justice is concerned with perceptions of fairness of the process with which resources are allocated. Thus, while distributive justice refers to the fairness of the ends, procedural justice emphasizes the means used to achieve those ends (Greenberg, 1990). More recently, Bies and colleagues (e.g., Bies, 1987; Bies \& Moag, 1986; Bies \& Shapiro, 1987) argued that the fairness with which people are treated during the resource exchange is also a critical dimension. This interactional form of justice refers to communication processes and the treatment of individuals during the exchange (Cropanzano \& Greenberg, 1997).

The relationship between distributive and interactional justice is of particular interest to this study, as it is central in validity assessments of two competing theories on the 'fair process effect' - the tendency for outcome evaluations and subsequent behavior to be influenced by perceptions of procedural justice (Van den Bos et al., 1997). Procedural justice in this context refers to both structural and interpersonal aspects of the process. Fairness heuristic theory (van den Bos, Lind, Vermunt, \& Wilke, 1997) argues that as people seldom have access to information about other people's outcome they must rely instead on readily available information. Thus procedural justice is used, in a heuristic manner, to shape impressions of overall justice. However, when information of the outcome of others is available then this information is accorded greater weight than procedural information. Indeed, Van den Bos and colleagues go so far as to suggest that when social comparison equity information is available one does not need procedural fairness to construct outcome judgments (Van den Bos et al., 1997 p. 1043). 
Conversely, fairness theory (Folger \& Cropanzano, 1998; 2001) claims that interactional justice may affect outcome evaluations more strongly than either procedural or distributive justice. According to Folger and Cropanzano (1998), violations of interactional justice often seem to be deliberate and freely chosen. In contrast, potential ambiguities exist for evaluating actions on the basis of procedural or distributive justice. In summary, both fairness heuristic and fairness theory maintain that process issues affect outcome evaluations although the former theory claims that the strength of this effect varies with social comparison information.

Collie, Sparks, and Bradley (2000), the first to empirically test both theories in a service failure context, investigated the effect of interactional justice, that is, the interpersonal aspect of the process, and the comparison to the outcome of others on fairness perceptions and satisfaction. They found that interpersonal treatment of customers significantly affected evaluations of outcome fairness and satisfaction, even when information about the outcome of others is known; knowledge of the outcome of others influenced respondents' evaluation of fairness but did not extend to satisfaction with the service encounter nor to future intentions towards the service provider. The authors concluded that interactional justice has a larger and more pervasive influence on customer evaluations than social comparison equity information, thereby lending support to Cropanzano and Folger's (1998) fairness theory. Yet again, this study assessed the impact of interactional justice and social comparison equity information in a single service provider context only. Therefore, the question is whether interactional justice also has a larger and more pervasive influence on customer evaluations than social comparison equity information in a multiple service provider setting, and how each service provider involved in the service failure event will be affected.

As interactional justice is concerned with aspects such as friendliness, empathy, and respect, that is, elements that are displayed by the provider in the service encounter, interactional justice evaluations are likely to be associated with a particular employee of the service provider or the service provider at large. Therefore, it is proposed that interactional justice has the greatest impact on the evaluation of, and behavior towards, the airline that deals with the service failure.

Based on a review of the pertinent literature the following hypotheses are advanced:

$\mathrm{H}_{1.1}$ : The airline that deals with the service failure event is likely to experience the greatest impact on consumer evaluations and behavior from a combined effect of 
pre-consumption mood and interactional justice, compared to its partner airline and the alliance.

$\mathrm{H}_{1.2}$ : The airline that deals with the service failure event is likely to experience the greatest impact on consumer evaluations and behavior from a combined effect of pre-consumption mood and distributive justice, compared to its partner airline and the alliance.

$\mathrm{H}_{2.1}$ - The airline that deals with the service failure event is likely to experience the greatest impact from interactional justice on consumer evaluations and behavior, compared to the partner airline and the alliance.

$\mathrm{H}_{2.2}$ - Consumer evaluations and behavior will vary directly with interactional justice, regardless of whether the outcome of others is known or not.

\section{METHOD}

\section{Research Design}

A 2 (Pre-Consumption Mood (PCM): positive versus negative) x 2 (Interactional Justice (IJ): high versus low) x 2 (Distributive Justice - Outcome Other (DJ- OO) - better versus unknown) between-subjects experimental design was adopted. In addition, a within-subject variable, 'Entity,' was included (home carrier, partner airline, alliance). The dependent variables measured were anger, satisfaction, and repeat purchase intentions for all three entities.

\section{Stimulus Material}

The stimulus material utilized in this study comprised two major components. First, a scenario designed to invoke pre-consumption mood was included, followed by an open-ended question that elicited verbal protocols of respondents' thoughts and feelings. Second, the service failure/recovery scenario was presented. Eight scripts were developed on the basis of interviews with airline executives and frequent travelers, in addition to reviews of service failure episodes relayed in various airline-related publications. Scenarios were identical except for manipulations of the three independent variables, depicting a service situation that involved two alliance partner airlines and the alliance on a code-shared flight (the airline the customer is loyal to - home carrier, the partner airline that dealt with the service failure, and the alliance). The home carrier caused the service failure by neglecting to communicate an upgrade request at a time when the flight operated by the partner airline was overbooked. The home carrier only offered an apology 
when the consumer relayed the incident in writing to the airline upon completion of the journey. Pre-tests with undergraduate students in the United States confirmed that these scripts were meaningful and realistic. Next, respondents were asked to answer questions relating to the dependent variables of interest. Finally, manipulation and realism check items were presented, followed by basic demographic questions. A sample of a scenario script is provided in Appendix A.

\section{Independent Variables}

Pre-consumption mood, interactional justice, and distributive justice (outcome others) were manipulated. Pre-consumption mood was operationalized as positive versus negative, and was induced by a scenario that made reference to both stimulus-induced emotion (service delivery of another service provider) and ambient mood (physical surroundings and personal well-being) (Isen, 1997), that is, pre-consumption mood was not related to the service provider who was assessed subsequent to the service failure event.

Interactional justice was operationalized as high versus low. The key dimensions of interactional justice included in the scenario related to staff empathy, attitude towards and respect for the customer, in addition to effort devoted to resolve the service failure. In the high IJ condition staff was attentive, polite, and respectful of the customer, displayed empathy, and made an effort to resolve the service problem. In contrast, in the low IJ condition, staff did not pay attention to the customer, was rude and disrespectful, did not display empathy nor expended much effort to rectify the problem.

Distributive justice was operationalized in the form of the knowledge of the outcome of others, with the outcome of others either 'better' or 'unknown', adopting the approach by Collie and colleagues (2000). In the 'DJ-OO Better' condition reference was made to the fact that all other members of the travel party were able to travel on the flight and only the respondent had to take a later flight, and consequently change further trip arrangements. In the 'DJ-OO unknown' condition no reference was made to a differential outcome.

\section{Dependent Measures}

Anger, satisfaction, and repeat purchase intentions were the dependent measures. All dependent measures were single item measures. Although multiple item scales are often preferred, single item measures were selected for this study due to one key reason. The dependent measures had to be obtained not only for one but three entities (home carrier, partner airline, 
alliance), thus resulting in a significant amount of information to be obtained. While multiple measures might be preferable, there is considerable precedent for single item use in previous research (LaBarbera \& Mazursky, 1983; Mittal et al., 1998). Anger, satisfaction, and repeat purchase intentions measures required a response on a 7-point scale $(1=$ strongly disagree, 7 = strongly agree). The anger measure was adopted from Richins (1997), while the satisfaction and repeat purchase intention measures were adopted from Crosby and Stephens (1987) and Zeithaml, Berry, and Parasuraman (1996) respectively.

\section{Sample and Procedure}

A convenience sample of 255 undergraduate students was drawn from a university in the Eastern United States. The sample was equally divided in terms of gender, and respondents' mean age was 21 years ( $\mathrm{SD}=1.8$ ). About $40 \%$ of the sample had flown within the United States between 2-6 times in the previous year, with another quarter of respondents having flown once. A quarter of respondents reported travel frequency within the same range for international travel.

A booklet containing one of the eight scenarios and a battery of questions relating to the dependent variables, manipulation and realism checks, and descriptive measures was distributed to respondents at a large university in the Eastern United States during a one-hour class period in October 2003. University ethics approval was obtained prior the administration of the study. At the beginning of the session one of the authors outlined the context of the research setting, without identifying the specific research interest. Next, students were informed that as a token of appreciation a prize draw for several small cash incentives and souvenirs would be held immediately following the data collection. In total, 20 cash incentives of US\$ 5, and 10 guidebooks were offered as prizes for completing the questionnaire. Each participant was then issued a booklet containing one version of the service scenario and the response measures. Distribution of the booklets was at random, with the treatment conditions being mixed prior distribution. Participants were instructed to read the scenarios, imagine that they were the customer depicted, and answer the questions accordingly. Completion time was approximately 25 minutes. All 255 students returned the booklet at the end of the class period; the option to enter the prize draw was taken up by $94 \%$ of respondents. During debriefing, no one appeared to know the true purpose of the study. Following the debriefing, the prize draw was held. 


\section{RESULTS}

Prior to the application of the primary repeated multivariate analysis of variance (MANOVA) technique, a preliminary data check was conducted (Hair, Anderson, Tatham, \& Black, 1995). To ensure assumptions of MANOVA were met, 14 cases were deleted. Thus, a total of 241 cases were available for the main analysis.

\section{Realism and Manipulation Checks}

Study participants were asked to respond to scenario scripts by imagining themselves in the role of the customer. Therefore, several measures assessing the realism of the provided scenarios were established (Wilson \& McNamara, 1982). Respondents found the service problem and its handling realistic, and could adopt the role of the customer $(\mathrm{M}=5.39 ; 5.31 ; 5.15$ respectively on a 7-point scale). Realism checks conducted for each of the eight scenarios confirmed the results of realism checks at the aggregate level.

Checks also confirmed that the manipulations for the two independent variables - preconsumption mood and interactional justice - were successful. The effectiveness of the preconsumption mood manipulation was ascertained with the Mood Short Form Scale (MSF), developed by Peterson and Sauber (1983). Respondents evaluated their mood on 7-point scales (1 = strongly disagree; 7 = strongly agree), relating to four items: "Currently I am in a good mood," “As I answer these questions I feel very cheerful," "For some reason I am not very comfortable right now," and “At this moment I feel edgy or irritable.” Subjects in the positive mood condition displayed significantly higher ratings on the global mood scale than subjects in the negative mood condition $\left(\mathrm{M}_{\text {positive mood/negative } \operatorname{mood}}=4.71 / 2.61 ; \mathrm{t}=4.74, p<.001\right)$.

The effectiveness of the interactional justice manipulation was ascertained with two questions that focused on the interpersonal aspects of politeness and helpfulness, consistent with previous studies (e.g., Blodgett et al., 1997; Collie, et al., 2000). These questions were: "The representative of Airline $\mathrm{C}$ treated me politely" and "The representative of Airline $\mathrm{C}$ was very helpful”. Respondents in the high interactional justice condition exhibited significantly higher ratings on the IJ manipulation scale than those in the low interactional justice condition $\left(\mathrm{M}_{\text {hightJ/low }}\right.$ IJ $=4.33 / 2.21 ; \mathrm{t}=12.49, p<.001)$. No manipulation check item was included for the two distributive justice conditions in the form of the knowledge of the outcome of others as it was not feasible to ascertain from respondents in the 'outcome of others unknown' condition perceptions on differential outcomes. 


\section{Consumer Evaluations and Behavior}

A 2 (PCM) x 2 (IJ) x 2 (DJ-OO) x 3 (Entity) repeated measures MANOVA examined differences in anger, satisfaction, and repeat purchase intention ratings for the home carrier, the partner airline, and the alliance. The within-subject variable was entity; that is, the home carrier, the partner airline, and the alliance. Pre-consumption mood, interactional and distributive justice were the between-subject independent variables.

Results revealed significant main and interaction effects for interactional justice only. Significant multivariate statistics and univariate results are presented in Table 1. The Bonferroni correction factor, used at the univariate level, and resulting in a new alpha level of $p<.017$, was applied to reduce the chance of a Type I error, in other words, finding a significant result when in fact there was none. Simple effects and simple contrasts were conducted at the .05 level.

\section{Interactional Justice}

A significant overall multivariate between-subject main effect for Interactional Justice ( $F$ $(3,224)=3.54, p<.05$, partial $\left.\eta^{2}=.045\right)$ was found when assessing the effects on anger, satisfaction, and repeat purchase intentions. However, when the results of the dependent variables were considered separately, these differences reached statistical significance using a Bonferroni adjusted alpha level of .017 for satisfaction only. Analysis of the descriptive statistics revealed that respondents in the high IJ justice condition expressed greater satisfaction than respondents in the low IJ justice condition (satisfaction: $\mathrm{M}_{\text {high IJ/low IJ }}=3.19 / 2.79$ ).

\section{Entity}

There was a significant multivariate main effect for Entity $(F(6,221)=6.24, p<.001$, partial $\eta^{2}=.145$ ). Assessing the results of the dependent variables separately, these differences reached statistical significance using a Bonferroni adjusted alpha level of .017 for anger and repeat purchase intentions.

These main effects were subsumed within a significant overall multivariate interaction effect between interactional justice and entity $\left(F(6,221)=4.46, p<.001\right.$, partial $\left.\eta^{2}=.108\right)$ Univariate results showed a significant effect on anger and satisfaction. The means for the dependent variables for the three entities are shown in Table 2 and the interaction effects are graphically displayed in Figures 1 and 2. 
Simple effect tests revealed that when IJ was high, anger and satisfaction varied depending on the entity evaluated (anger: $F(2,117)=7.55, p<.001$; satisfaction $F(2,117)=$ 5.72, $p<.01$ ). Contrasts revealed that respondents were significantly more satisfied with the partner airline than the home carrier $(p<.01)$. Furthermore, there were significant differences in anger $(p<.001)$ and satisfaction ratings $(p<.01)$ for the partner airline versus the alliance, with respondents being more angry and less satisfied with the alliance than the partner airline.

When low IJ was employed by the partner airline, anger and satisfaction ratings varied again for the three entities under investigation (anger: $F(2,117)=6.35, p<.01$; satisfaction: $F$ $(2,116)=5.96, p<.01)$. Contrasts indicated that customers were angrier $(p<.001)$ and less satisfied $(p<.01)$ with the partner airline than with the home carrier. There was a significant difference in ratings for anger $(p<.01)$ between the home carrier and the alliance, but not for satisfaction $(p>.05)$.

Simple effects tests revealed that when the partner airline was evaluated, subjects gave significantly higher ratings for anger $(F(1,236)=19.53, p<.001)$ and lower ratings for satisfaction $(F(1,237)=29.99, p<.001)$ if low IJ was employed compared to high IJ. There was no significant difference at the .05 level between the ratings associated with IJ when either the home carrier or the alliance were evaluated in terms of anger and satisfaction.

\section{Pre-Consumption Mood}

A significant overall multivariate interaction effect between pre-consumption mood and entity $\left(F(6,221)=4.46, p<.001\right.$, partial $\left.\eta^{2}=.108\right)$ was also detected. Univariate results showed a significant effect on anger. The means for the dependent variable for the three entities are shown in Table 3 and the interaction effect is graphically displayed in Figure 3.

Simple effect tests revealed that when PCM was positive, anger varied depending on the entity evaluated (anger: $F(2,116)=12.68, p<.001)$. Contrasts revealed that respondents directed significantly more anger towards the alliance compared to the partner airline $(p<.01)$ and the home carrier $(\mathrm{p}<.001)$. When PCM was negative, anger ratings did not vary significantly for the three entities investigated. 
Simple effects tests revealed that when the alliance was evaluated, subjects gave significantly higher ratings for anger $(F(1,236)=19.53, p<.001)$ if PCM was positive compared to PCM being negative. There was no significant difference at the .05 level between the ratings associated with PCM when either the home carrier or the partner airline were evaluated in terms of anger.

\section{DISCUSSION}

\section{Pre-consumption Mood}

The effect of pre-consumption mood caused by external factors was of interest in combination with service recovery measures employed by the provider. Hypothesis $\mathrm{H}_{1.1}$ was not supported; that is, the mood consumers were in prior the service encounter and the fact that staff of the airline that dealt with the service failure was either polite and helpful or rude and unhelpful did not appear to impact consumer evaluations and behavior. This is a rather surprising result, especially in light of previous studies (Price et al., 1995; Smith \& Bolton, 2002). However, the influence of pre-consumption mood on attributions of responsibility for the service failure, and the fact that particularly in the positive pre-consumption mood condition the partner airline that dealt with the service failure was attributed less responsibility than the home carrier and the alliance, help explain this result. Similarly, Hypothesis $\mathrm{H}_{1.2}$ was also not supported in that preconsumption mood together with distributive justice (in the form of the knowledge of the outcome of others) did not have an impact on the dependent measures.

However, pre-consumption mood did have a significant effect on the anger directed towards the three entities involved in the service failure. Interestingly, this was only the case for those in the positive pre-consumption mood condition where the greatest anger was directed towards the alliance, followed by the partner airline and then the home carrier. It appears that those in a negative mood rated each entity similarly, whereas those in a positive mood reported feeling of greater anger toward the more distant entities.

\section{Service Recovery Measures}

Study results provided support for hypotheses $\mathrm{H}_{2.1}$ and $\mathrm{H}_{2.2}$. First, the main effect for interactional justice confirmed that consumer evaluations vary directly with the level of interactional justice employed by a service provider in a service failure event, with a high level of IJ leading to greater satisfaction. This is consistent with previous research on the impact of interactional justice (e.g., Hocutt et al., 1997; Tax et al., 1998). Furthermore, the absence of an interaction effect between interactional justice and distributive justice - outcome of others lent 
support to Hypothesis $\mathrm{H}_{2.2}$. Consumer responses varied directly with interactional justice, regardless of whether the outcome of others was known or not, thus confirming Collie and colleagues' (2000) assertion that interactional justice has both a larger and more pervasive influence on customer evaluation than comparison equity information. This result also provides further support for Folger and Cropanzano’s (1998) argument that interactional justice is a critical consideration in a service failure/recovery situation.

The main effect for interactional justice was, however, further qualified by an interaction effect that provided support for Hypothesis $\mathrm{H}_{2.1}$; in other words, it confirmed that the airline that dealt with the service failure experienced the greatest impact on consumer evaluations and behavior. In particular, consumer evaluations and behavior varied significantly for the partner airline only; that is the airline that dealt with the service failure. If the partner airline employed high interactional justice, satisfaction ratings were significantly higher than for either the home carrier or the alliance. Thus, it appears that the airline that deals with a service failure, even if it has not caused the failure, has an opportunity to strengthen its position relative to the partner airline by handling the service recovery in a satisfactory manner.

Conversely, if the partner airline employed low interactional justice, respondents were angrier and more dissatisfied. High anger and low satisfaction ratings are to be expected as a result of low interactional justice, as shown in previous studies (e.g., Price et al., 1995). In this instance, however, the partner airline was not the airline that caused the service failure. Thus, while the partner airline did not handle the service failure in a satisfactory manner, it would not have been required to deal with a service failure, were it not for the actions of its partner airline, the customer's home carrier. Indeed, in this study, the home carrier that caused the service failure received the highest satisfaction rating when the partner airline employed low interactional justice. That is despite the home carrier being perceived as more responsible for the service failure than the partner airline. While the previous experience and relationship with the home carrier may in part explain this result, it could also be speculated that the actions of the partner airline with the service failure serves to reinforce the relationship with the home carrier. Conversely, the positive handling of the service failure by the partner airline appears to also have a positive effect on the home carrier. 
Finally, analysis of descriptive statistics revealed that the more interactional justice was displayed by staff of the partner airline that dealt with the service failure the less responsible that airline was held. At the same time more responsibility was attributed to the home carrier and the alliance. In contrast, when interactional justice was low, respondents were ready to hold the partner airline responsible. Such an attribution of responsibility is consistent with fairness theory that proposes that interactional conduct provides an easily observable basis for attributing responsibility (Cropanzano \& Folger, 1998).

\section{MANAGERIAL IMPLICATIONS}

This research for the first time highlights potential negative repercussions for an airline resulting from its affiliation with an alliance and its partner airlines. It demonstrates likely problems for airlines in an alliance that can be negatively affected by a service failure event of a partner airline, first via a negative evaluation and consequently, by customer dissatisfaction, negative word-of-mouth, and ultimately, reduced loyalty. Airlines also have to recognize the potential competition for their business if a partner airline deals very well with a service failure, with this partner airline potentially featuring more prominently in the customer's choice of an airline to patronize in the future.

Several key managerial implications emerge. In the first instance, it is crucial for an airline to join an alliance that can not only provide the desired operational benefits but one in which alliance partners have similar service philosophies and place similar emphasis on the satisfactory resolution of service failure events. Yet, a careful review of the major global airline alliances currently in existence reveals that they not only bring together airlines with different cultural backgrounds but also those with a volume orientation opposed to a service orientation. Consequently, there is a need for greater cooperation among alliance airlines in devising and implementing strategies to deal with service failure events in flights that are serviced by two or more partner airlines.

In order to strengthen relationships with their customers, especially the most frequent and profitable ones, it is essential for alliance airlines to be no longer only concerned about their own service standards and policies relating to service failure events and recovery but to be also mindful of those of their partner airlines. In the first instance, that would translate into readily offering solutions to a customer who has communicated a service failure event by one of the partner airlines. Clearly, having spent valuable time to relate such an incident to the airline s/he is 
loyal to means that the expectations are higher than simply receiving a standard reply without acceptance of any responsibility.

Next, when an airline solicits feedback from its customers, it may also ascertain customer experiences on flights operated by partner airlines via a code-share agreement with the express purpose of possibly offering remedial action in case of service problems. Such action would indicate to the customer that the airline not only has an understanding of the complexity of the relationships in an alliance setting but also that it is proactive in ensuring that the experience of its valued customers is of a standard they expect. As a potential source for conflict resolution, alliances may want to consider an alliance customer service center rather than leaving its customers alone in dealing with the various alliance partners, unnecessarily causing time delays and frustration.

\section{LIMITATIONS}

There were several delimitations incorporated into the research design. For example, it is acknowledged that 1) the research setting was confined to an airline alliance context, 2) the sample was purposely restricted to respondents of Western origin, 3) respondents were taken from a student population, and 4) contextual factors impacting consumer responses to a service failure event in a strategic alliance setting have been restricted arbitrarily. In addition to the stated delimitations, further limitations are acknowledged. First, this research involved an experiment, with respondents being randomly assigned to treatment conditions. Therefore, results have a high degree of internal validity (Cook \& Campbell, 1979). However, threats to the internal validity resulting from carry-over effects due to the use of a within-subject design were a possibility. Randomizing the ordering of scenario scripts and subjects reduced these threats. The use of hypothetical service failure scenarios is a second limitation of this research as it is difficult to stimulate the cognitive and emotional involvement generated by an actual service failure/recovery event. However, extensive pre-testing of the stimulus material and subsequent checks on the realism and identification with the role of the customer indicated a high degree of involvement of respondents. 


\section{FUTURE RESEARCH}

The findings of this study go some way to understanding consumer evaluations and behavior following a service failure in a strategic alliance setting, yet much remains unresolved. Accordingly, several areas are suggested for future research. These research areas are investigations in 1) different multiple service provider settings, and 2) different cultural settings.

Research findings may be validated in settings other than the strategic airline alliance setting used in this study. For example, it may be of interest whether the findings of this research are applicable only to horizontal alliances; that is, alliances that bring together service providers offering the same service product to the consumer, such as air travel, or whether they are equally applicable in vertical alliances; that is, alliances that bring together service providers offering different service products, such as air travel and hotels. Similarly, future research may also assess whether research findings extend to more loosely integrated service network (e.g., Smith \& Tax, 2005).

Future research could also assess whether the findings of this research that drew on consumers of Western origin transfer to consumers with a different cultural background. Several studies noted differences in consumer evaluations and behavior resulting from service failure events (e.g., Watkins \& Liu, 1996; Wee \& Cheong, 1991). Thus, it is conceivable that such differences in cultural background also affect consumer responses to a service failure event in multiple service provider settings. In particular, the impact of social identity may vary between consumers of different cultural backgrounds, with status and recognition being afforded different importance in different cultures.

Future research could also investigate service failure/recovery in multiple entities looking more specifically at communication issues. Drawing on communication literature to complement the justice research base of this article could provide further insight to the service recovery process. 


\section{REFERENCES}

Adams, J.S. 1965. Inequity in social exchange. Edited by L. Berkowitz. Vol. 2, Advances in experimental social psychology. New York: Academic Press. 267-299.

Bagozzi, R.P., M. Gopinath, and P.U. Nyer. 1999. The Role of Emotions in Marketing. Journal of the Academy of Marketing Science 27 (2):184-206.

Bies, R.J. 1987. The predicament of injustice: The management of moral outrage. In Research in organizational behavior, edited by L. L Cummings \& B. M. Staw. Greenwich, CT: JAI Press. 289-319

Bies, R.J., and J.S. Moag. 1986. Interactional justice: Communication criteria for fairness. Edited by B. Sheppard. Vol. 1, Research on negotiation in organizations. Greenwich, CT: JAI. 43-55

Bies, R.J., and D.L. Shapiro. 1987. Interactional fairness judgments: The influence of causal accounts. Social Justice Research 1:199-218.

Bitner, M.J., and A. R. Hubbert. 1994. Encounter Satisfaction Versus Overall Satisfaction Versus Quality: The Customer's Voice. In Service quality: new directions in theory and practice, edited by R. T. Rust and R. L. Oliver. Thousand Oaks, CA: Sage Publication. 72-94.

Bitner, M.J., B.H. Booms, and M.S. Tetreault. 1990. The Service Encounter: Diagnosing Favorable and Unfavorable Incidents. Journal of Marketing 54 (January):71-84.

Blodgett, J.G., D.J. Hill, and S. S. Tax. 1997. The effects of distributive, procedural and interactional justice on service complaint behavior. Journal of Retailing 73 (2):185-210.

Boshoff, C. , and J. Leong. 1998. Empowerment, attribution and apologizing as dimensions of service recovery: an experimental study. International Journal of Service Industry Management 9 (1):24.

Cohen, J.B., and C.S. Areni. 1991. Affect and consumer behavior. In Handbook of consumer behavior, edited by T. S. Robertson and H. H. Kassarjian. Englewood Cliffs, NJ: Prentice Hall. 188-240.

Collie, T.A., B. A. Sparks, and G. L. Bradley. 2000. Investing in interactional justice: A study of the fair process effect within a hospitality failure context. Journal of Hospitality \& Tourism Research 24 (4):448-472.

Cook, T. D., and D. T. Campbell. 1979. Quasi-experimentation : design \& analysis issues for field settings. Boston: Houghton Mifflin Company.

Cropanzano, R., and J. Greenberg. 1997. Progress in organizational justice: Tunneling through the maze. In International Review of Industrial and Organizational Psychology, edited by C. L. Cooper and I. T. Robertson. New York: Wiley \& Sons.

Crosby, L.A., and N. Stephens. 1987. Effects of Relationship Marketing on Satisfaction, Retention, and Prices in the Life Insurance Industry. Journal of Marketing Research 24 (4):404411. 
DeWitt, T., and M. K. Brady. 2003. Rethinking service recovery strategies. Journal of Service Research 6 (2):193-207.

Dube, L., and M. Maute. 1996. The antecedents of brand switching, brand loyalty and verbal responses to service failure. In Advances in Services Marketing and Management, edited by T. A. Swartz, D. E. Bowen and S. W. Brown. Greenwich, CT: JAI Press.

Folger, R., and R. Cropanzano. 1998. Organizational justice and human resource management. Thousand Oaks, CA: Sage Publications.

Folger, R., and R. Cropanzano. 2001. Fairness theory: Justice as accountability. Edited by J. G. R. Cropanzano, Advances in organizational justice. Stanford, CA: Stanford Univ. Press. 1-55.

Frijda, N.H. 1986. The Emotions. Cambridge, UK: Cambridge University Press.

Gardner, M.P. 1985. Mood States and Consumer Behavior: A Critical Review. Journal of Consumer Research 12 (December):281-300.

Greenberg, J. 1990. Organizational justice: Yesterday, today, and tomorrow. Journal of Management 16:399-432.

Gittell, J.H. 2002. Relationships between service providers and their impact on customers. Journal of Service Research 4 (4):299-311

Hair, J., R.E. Anderson, R.L. Tatham, and W.C. Black. 1995. Multivariate data analysis with readings. 4 ed. Upper Saddle River, NJ: Prentice-Hall.

Hocutt, M. A., G. Chakraborty, and J. C. Mowen. 1997. The impact of perceived justice on customer satisfaction and intention to complain in a service recovery. Advances in Consumer Research 24:457-463.

Isen, A. M. 1987. Positive affect, cognitive processes and social behavior. Edited by L. Berkowitz., Advances in experimental social psychology. New York: Academic. 203-253

Keaveney, S.M. 1995. Customer switching behavior in service industries: An exploratory study. Journal of Marketing 59 (April):71-82.

LaBarbera, P.A., and D. Mazursky. 1983. A longitudinal assessment of consumer satisfaction/dissatisfaction: The dynamic aspect of the cognitive process. Journal of Marketing Research 20:393-404.

Liljander, V., and J. Mattsson. 2002. Impact of customer preconsumption mood on the evaluation of employee behavior in service encounters. Psychology and Marketing 19 (10):837860.

Mano, H., and R. L. Oliver. 1993. Assessing the Dimensionality and Structure of Consumption Experience: Evaluation, Feeling, and Satisfaction. Journal of Consumer Research 20:451-466.

Mattila, A., and J. Wirtz. 2000. The role of preconsumption affect in postpurchase evaluation of services. Psychology \& Marketing 17:587-605. 
McColl-Kennedy, J. R., and B. A. Sparks. 2003. Counterfactual thinking based model of service recovery. Journal of Service Research 5 (3):251-266.

McCollough, M.A., L.L. Berry, and M.S. Yadav. 2000. An empirical investigation of customer satisfaction after service failure and recovery. Journal of Service Research 3 (2):121-137.

Mittal, V., J.M. Katrichis, and P. Kumar. 2001. Attribute performance and customer satisfaction over time: Evidence from two field studies. Journal of Services Marketing 15 (4/5):343-356.

Mittal, V., P. Kumar, and M. Tsiros. 1999. Attribute performance, satisfaction, and behavioral intentions over time: a consumption system approach. Journal of Marketing 63 (2, April):88-101.

Oliver, R.L. 1993. A conceptual model of service quality and service satisfaction: Compatible goals, different concepts. In Advances in services marketing and management: Research and practice, edited by T. A. Swartz, D. E. Bowen and S. W. Brown. Greenwich, CT: JAI.

Price, L.L., E.J. Arnould, and P. Thierney. 1995. Going to extremes: Managing service encounters and assessing provider performance. Journal of Marketing 59 (April):83-97.

Smith, A.K., and R.N. Bolton. 1998. An experimental investigation of customer reactions to service failure and recovery encounters: paradox of peril? Journal of Services Research 1: 65-81.

Smith, A.K., and S.S. Tax. 2005. A Pound of Flesh, But From Whom? Assessing Failure \& Recovery In A Service Network. Paper read at 2005 SERVSIG Conference, at Singapore.

Smith, A.K., R.N. Bolton, and J.Wagner. 1999. A model of customer satisfaction with service encounters involving failure and recovery. Journal of Marketing Research 36 (3): 356-372.

Sparks, B.A., and J.R. McColl-Kennedy. 1998. The application of procedural justice principles to service recovery attempts: Outcomes for customer satisfaction. Advances in Consumer Research 25:156-161.

Tax, S.S., S.W. Brown, and M. Chandrashekaran. 1998. Customer evaluations of service complaint experiences: Implications for relationship marketing. Journal of Marketing 62 (April):60-76.

Thibaut, J., and L. Walker. 1975. Procedural justice: A psychological analysis. Hillsdale, NJ: Erlbaum.

Van den Bos, K., H. A.M. Wilke, E. A. Lind, and R. Vermunt. 1998. Evaluating outcomes by means of the fair process effect: Evidence for different processes in fairness and satisfaction judgments. Journal of Personality and Social Psychology 74 (6):1493-1503.

Van den Bos, K., E. A. Lind, R. Vermunt, and H. A. M. Wilke. 1997. How do I judge my outcome when I do not know the outcome of others? The psychology of the fair process effect. Journal of Personality and Social Psychology (72):1034-1046.

Watkins, H.S., and R. Liu. 1996. Collectivism, individualism and in-group membership: implications for consumer complaining behaviors in multicultural contexts. Journal of International Consumer Marketing 8 (3/4):69-96. 
Weber, K. 2002. Consumer Perceptions and Behavior: Neglected Dimensions in Research on Strategic Airline Alliances. Journal of Travel \& Tourism Marketing 13 (4):27-46.

Wee, C.H., and C. Chong. 1991. Determinants of consumer satisfaction/dissatisfaction towards dispute settlements in Singapore. European Journal of Marketing 25 (10):6-16.

Westbrock, R.A., and R.L. Oliver. 1991. The dimensionality of consumption emotion patterns and consumer satisfaction. Journal of Consumer Research 18:84-91.

Wilson, P. \& McNamara, J. R. (1982). How perceptions of a simulated physician-patient interaction influence intended satisfaction and compliance. Social Science and Medicine, 16, 1699-1704.

Zeithaml, V. A., L. L. Berry, and A. Parasuraman. 1996. The behavioral consequences of service quality. Journal of Marketing 60 (2):31-46. 
Table 1

Summary of Significant MANOVA Results

\begin{tabular}{|c|c|c|c|c|c|c|}
\hline \multirow{2}{*}{ Source } & \multirow[b]{2}{*}{ df } & Multivariate & \multicolumn{4}{|c|}{ Univariate } \\
\hline & & $\mathbf{p}$ & $\eta_{p}^{2}$ & $\mathbf{F}$ & $\mathbf{p}$ * & $\eta_{p}^{2}$ \\
\hline \multicolumn{7}{|l|}{ MAIN EFFECTS } \\
\hline Interactional Justice & {$[3,224] 3.54$} & .016 & .045 & & & \\
\hline Satisfaction & & & & 8.18 & .005 & .035 \\
\hline Entity & {$[6,221] 6.24$} & .000 & .145 & & & \\
\hline Anger & & & & 5.39 & .005 & .023 \\
\hline Repeat Purchase Intentions & & & & 10.96 & .000 & .046 \\
\hline \multicolumn{7}{|l|}{ INTERACTION EFFECTS } \\
\hline Interactional Justice $x$ Entity & {$[6,221] 4.46$} & .000 & .108 & & & \\
\hline Anger & & & & 8.89 & .000 & .038 \\
\hline Satisfaction & & & & 9.58 & .000 & .041 \\
\hline Pre-consumption Mood x Entity & {$[6,221] 2.19$} & .045 & .056 & & & \\
\hline Anger & & & & 5.234 & .006 & .023 \\
\hline
\end{tabular}


Table 2

Descriptives for Anger and Satisfaction - Interactional Justice x Entity Interaction

\begin{tabular}{|c|c|c|c|c|c|c|}
\hline \multirow[t]{2}{*}{ Interactional Justice } & \multicolumn{3}{|c|}{ High IJ } & \multicolumn{3}{|c|}{ Low IJ } \\
\hline & $M$ & $S D$ & $n$ & $M$ & $S D$ & $n$ \\
\hline \multicolumn{7}{|l|}{ Anger } \\
\hline Home Carrier & 5.41 & 1.54 & 116 & 5.35 & 1.62 & 118 \\
\hline Partner Airline & 5.00 & 1.81 & 116 & 5.94 & 1.43 & 118 \\
\hline Alliance & 5.75 & 1.49 & 116 & 5.81 & 1.45 & 118 \\
\hline \multicolumn{7}{|l|}{ Satisfaction } \\
\hline Home Carrier & 2.97 & 1.82 & 116 & 2.98 & 1.67 & 118 \\
\hline Partner Airline & 3.61 & 1.77 & 116 & 2.47 & 1.41 & 118 \\
\hline Alliance & 2.99 & 1.66 & 116 & 2.93 & 1.65 & 118 \\
\hline
\end{tabular}

Anger and satisfaction were measured on a 7-point scale (1 = 'strongly disagree,” 7 = ‘strongly agree') 
Table 3

Descriptives for Anger - Pre-consumption Mood (PCM) x Entity Interaction

Anger was measured on a 7-point scale (1 = 'strongly disagree,” 7 = 'strongly agree') 


\section{Table 4}

Scripts for the Manipulation of Independent Variables

\section{Pre-Consumption Mood (PCM)}

\section{Positive PCM}

You are staying with family friends in New York prior to your overseas trip. On the day of your flight your alarm goes off on time. You get up and take a nice, long shower and a leisurely breakfast with your hosts. The shuttle you had booked to get you to the airport arrives at the appointed time. Since it is early, traffic moves smoothly. The shuttle driver is very friendly and you have a pleasant conversation during the journey. When dropping you at the terminal entrance he is also helping you with your luggage. It's a warm day with blue sky and sunshine. You arrive at the check-in counter well in time. You are in a very good mood.

\section{Negative PCM}

You are staying with family friends in New York prior to your overseas trip. On the day of your flight your alarm does not go off on time. You get up and rush to take a quick shower, and don't have any time for breakfast with your hosts. The shuttle you had booked to get you to the airport does not arrive at the appointed time, and you have to call the company several times to inquire about its whereabouts. The shuttle finally arrives 40 minutes late. Since it is late now, traffic moves very slowly. The shuttle driver is very unfriendly and you don't have any conversation during the journey. When dropping you at the terminal entrance he is not helping you with your luggage. It's a cold day with dark sky and heavy rain. Since the shuttle driver dropped you at the wrong terminal you arrive at the check-in counter shortly before closing. You are in a very bad mood.

\section{Interactional Justice}

High IJ

The representative of British Airways carefully looks at and immediately recognises your membership card, politely listens, and seems very understanding, and in a sympathetic voice says: "I'm very sorry about this. You know the customers of our partner airline and the alliance are important to us. I'll see what I can do for you.”

Low IJ

The representative of British Airways barely looks at and does not seem to recognize your membership card nor listens, seems very agitated, and in an irritated voice says: "There is not much I can do at all. Overbooking is now very common among all airlines so this may happen

\begin{tabular}{|l|}
\hline Formatted \\
\hline Formatted \\
\hline Formatted \\
\hline Formatted \\
\hline
\end{tabular}
occasionally.” 


\section{Distributive Justice (Outcome Others)}

Better

However, the three college friends you are travelling with have all been checked-in for the original flight so that you are the only one who will have to fly six hours later and change the flight and train tickets for travel in Europe.

Unknown

No reference is made to a differential outcome for the members of the travel party. 


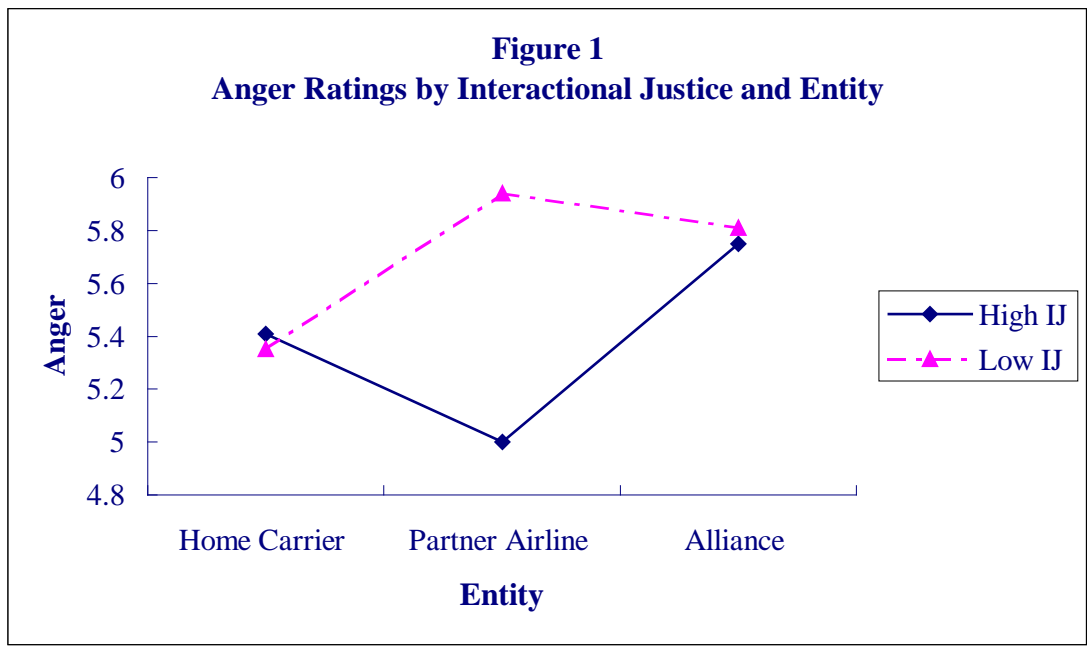




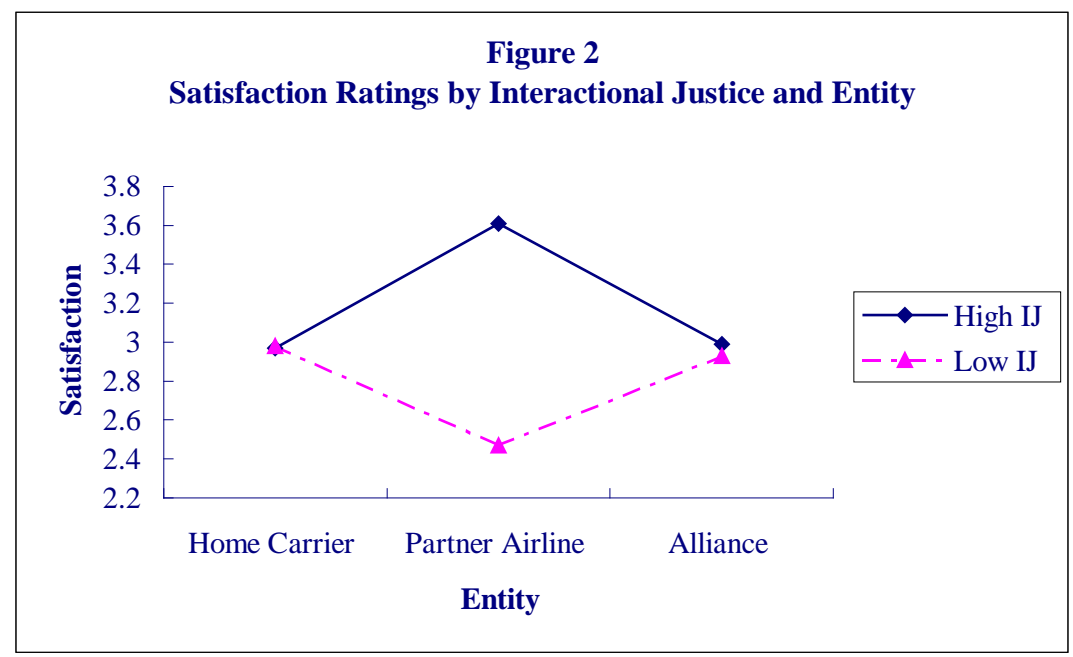




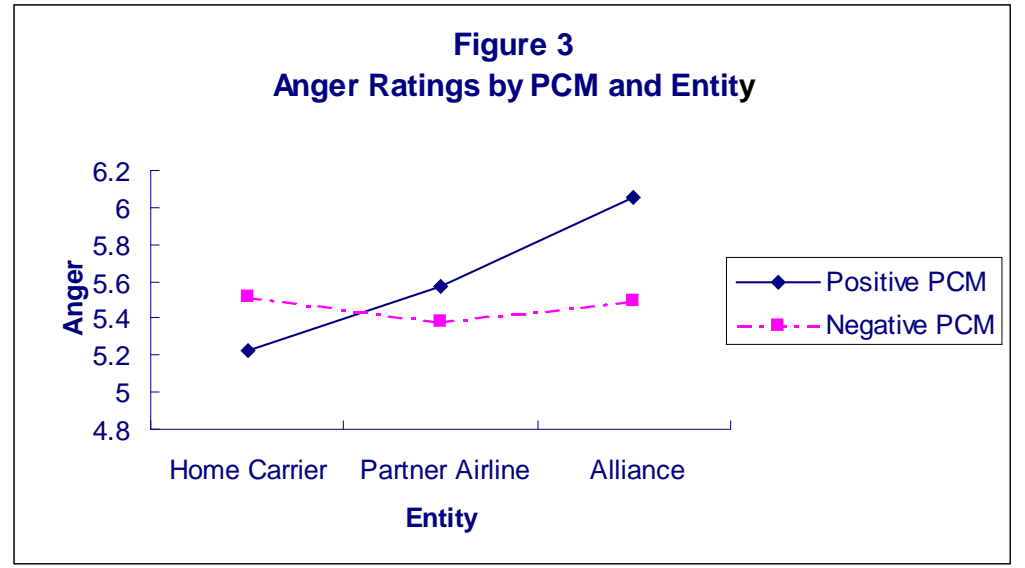

